\title{
Sensory Cortical Activity Is Related to the Selection of a Rhythmic Motor Action Pattern
}

\author{
Jennifer X. Li, ${ }^{1,3}$ 이oost X. Maier, ${ }^{4}$ Emily E. Reid, ${ }^{1}$ and Donald B. Katz ${ }^{1,2,3}$ \\ Departments of ${ }^{1}$ Psychology and ${ }^{2}$ Biology, and ${ }^{3}$ Volen National Center for Complex Systems, Brandeis University, Waltham, Massachusetts 02454 , and \\ ${ }^{4}$ Department of Neurobiology and Anatomy, Wake Forest School of Medicine, Winston-Salem, North Carolina 27157
}

Rats produce robust, highly distinctive orofacial rhythms in response to taste stimuli-responses that aid in the consumption of palatable tastes and the ejection of aversive tastes, and that are sourced in a multifunctional brainstem central pattern generator. Several pieces of indirect evidence suggest that primary gustatory cortex (GC) may be a part of a distributed forebrain circuit involved in the selection of particular consumption-related rhythms, although not in the production of individual mouth movements per se. Here, we performed a series of tests of this hypothesis. We first examined the temporal relationship between GC activity and orofacial behaviors by performing paired single-neuron and electromyographic recordings in awake rats. Using a trial-by-trial analysis, we found that a subset of GC neurons shows a burst of activity beginning before the transition between nondistinct and taste-specific (i.e., consumption-related) orofacial rhythms. We further showed that shifting the latency of consumption-related behavior by selective cueing has an analogous impact on the timing of GC activity. Finally, we showed the complementary result, demonstrating that optogenetic perturbation of GC activity has a modest but significant impact on the probability that a specific rhythm will be produced in response to a strongly aversive taste. GC appears to be a part of a distributed circuit that governs the selection of taste-induced orofacial rhythms.

Key words: coding; gustatory; orofacial; sensorimotor

\section{Significance Statement}

In many well studied (typically invertebrate) sensorimotor systems, top-down modulation helps motor-control regions "select" movement patterns. Here, we provide evidence that gustatory cortex (GC) may be part of the forebrain circuit that performs this function in relation to oral behaviors ("gapes") whereby a substance in the mouth is rejected as unpalatable. We show that GC palatability coding is well timed to play this role, and that the latency of these codes changes as the latency of gaping shifts with learning. We go on to show that by silencing these neurons, we can change the likelihood of gaping. These data help to break down the sensory/motor divide by showing a role for sensory cortex in the selection of motor behavior.

\section{Introduction}

Many basic behaviors are rhythmic (e.g., locomotion and respiration). The repeating patterns of muscle contraction and relaxation that underlie such behaviors are driven by central pattern generators (CPGs; Grillner, 1985), which in vertebrates typically reside in brainstem circuits (Jordan and Slawińska, 2011). While CPGs are well situated to quickly receive and process sensory input, they also receive considerable "top-down feedback" from cortex (Duysens and Van de Crommert, 1998; Hattox et al., 2002;

\footnotetext{
Received Nov. 2, 2015; revised March 14, 2016; accepted April 13, 2016

Author contributions: J.X.L. and D.B.K. designed research; J.X.L., J.X.M., and E.E.R. performed research; J.X.L. analyzed data; J.X.L., E.E.R., and D.B.K. wrote the paper.

This research supported by National Institutes of Health Grants R01-DC-6666 and R01-DC-7703 (to D.B.K.), and R03-DC-14017 (to J.X.M.).

The authors declare no competing financial interests.

Correspondence should be addressed to Donald B. Katz, Brandeis University, Department of Psychology, MS 062,

415 South Street, Waltham, MA 02454. E-mail: dbkatz@brandeis.edu.

DOI:10.1523/JNEUROSCI.3949-15.2016

Copyright $\odot 2016$ the authors $\quad 0270-6474 / 16 / 365596-12 \$ 15.00 / 0$
}

Cramer and Keller, 2006). The nature of this descending influence is unclear; one possibility is that cortex influences the selection of CPG rhythms, much as neuromodulation affects the rhythms produced by invertebrate CPGs (Marder et al., 2005; Friesen and Kristan, 2007; Vidal-Gadea et al., 2010).

One set of rhythmic behaviors easily observed in vertebrates is the oromotor rhythms induced by taste delivery. Upon receiving a drop of tastant, rats produce an initial bout of nonspecific intraoral licks, which transition into bouts of either ingestive [lateral tongue movements (LTMs)] or egestive (gapes) movements, depending on the palatability (hedonic value) of the taste (Grill and Norgren, 1978a; Travers and Norgren, 1986). The ingestive and egestic orofacial rhythms are driven by a common CPG residing in the intermediate and parvocellular zones of the reticular formation (Holstege et al., 1977; Travers et al., 2000; Chen et al., 2001; Travers et al., 2005).

Although this brainstem CPG is sufficient to generate the appropriate orofacial sequence in response to innately aversive or palatable stimuli (Grill and Norgren, 1978b), several lines of ev- 
idence suggest that activity in forebrain taste areas, including primary gustatory cortex (GC), may help to select the orofacial rhythm. GC projects directly to the CPG (Zhang and Sasamoto, 1990; Shammah-Lagnado et al., 1992; Travers et al., 1997), and stimulation of GC can induce changes in licking and rhythmic jaw movements (Sasamoto et al., 1990; Peng et al., 2015). Moreover, taste responses in GC become palatability related around the onset of ingestive/egestive behavior (Katz et al., 2001; Sadacca et al., 2012), and appear necessary for palatability-related responses to novel tastes (Stehberg et al., 2011; Moraga-Amaro et al., 2014). Finally, GC is crucial for changing the response of a rat from LTMs to gapes during taste learning (Kiefer and Orr, 1992; Schafe et al., 1998). These findings indicate that GC may be directly involved in the selection or driving of taste-related behavior-although it almost certainly performs these functions in cooperation with a much larger circuit including the amygdala, hypothalamus, and bed nucleus of the stria terminalis (BNST; Travers et al., 1997; see Discussion).

Here, we more directly test the hypothesis that GC plays a role in modulating the transition from nonspecific intraoral licks to gapes, but not in driving individual mouth movements, focusing on gapes to take advantage of the relative ease with which they can be reliably detected. Our approach was fourfold, as follows: (1) we examined the temporal relationship between the palatability relatedness of GC firing and behavior within a randomized taste delivery paradigm, predicting that palatability-related GC firing should emerge before taste specific behaviors; (2) we evaluated the change in GC firing before and during gaping, predicting a specific, direct correlation - that on a trial by trial basis, the first gape will be preceded by changes in firing rates, and that later gapes will not; (3) we used a cue to alter the latency of gaping, predicting that the altered latency of the behavior transition would similarly shift the timing of the GC neural responses; and (4) we used an optogenetic silencer to suppress GC activity [i.e., GC inactivation $(\mathrm{GCx})$ ] during taste processing, predicting that GCx would impact the production of gapes. Each prediction was borne out, allowing us to suggest that GC is one part-but only one part- of the distributed system that influences the transition from intraoral licks to gapes.

\section{Materials and Methods}

Subjects. We used adult (weight, 250-300 g) female Long-Evans rats (females were selected for docility; Charles River Laboratories) as subjects in the electrophysiology experiments $(N=6$ in no-cue experiments only; $N=3$ in cue experiments only; $N=9$ in both no-cue and cue experiments) and optogenetic inactivation experiments $(N=17$ virus injected rats; and $N=11$ controls). The same taste delivery paradigms were used for all groups of animals (see below). Throughout the study, rats were maintained on a $12 \mathrm{~h}$ light/dark schedule, with experiments taking place during the first third of the light period. Rats were weighed daily and observed to never drop to $<80 \%$ of their presurgery weight. All experimental methods were in compliance with National Institutes of Health guidelines and were approved in advance by the Brandeis University Institutional Animal Care and Use Committee.

Virus delivery surgery. Rats were infected with ArchT-expressing adeno-associated virus (AAV-CAG-ArchT-GFP, $2.5 \times 10^{11}$ particles $/ \mathrm{ml}$, obtained from the University of North Carolina Vector Core). To inject the virus into GC, we first exposed and cleaned the skull, and made craniotomies over GC (see below). We then inserted a glass micropipette (diameter, 12-18 $\mu \mathrm{m}$ ) containing viral particles suspended in a solution of PBS and Oregon Green 488 (Invitrogen) into GC. Three separate injections were made per hemisphere, at depths of 4.9, 4.7, and $4.5 \mathrm{~mm}$. Each injection deposited a total volume of $1.25 \mu \mathrm{l}$ in 25 discrete pulses ( $50 \mathrm{nl} /$ pulse, $7 \mathrm{~s}$ between each pulse). We used a Nanoject II Auto-
Nanoliter Injector (Drummond Scientific) to control pulse volume and delivery.

To ensure a high level of ArchT expression during the optogenetics experiments, the virus was injected 3 weeks before the implantation of optical fibers (Zhang et al., 2010). All cell types were similarly subject to infection and ArchT expression, a choice that ensured relatively consistent output inhibition; the inhibition of individual single cell types inevitably causes disinhibition of other cell types, thus mixing the impact of illumination (see also Discussion).

Virus-free control subjects were also implanted with optical fibers.

Electrode and optical fiber implantation surgeries. Before each surgery, we anesthetized the rat with an intraperitoneal injection of a ketamine/ xylazine cocktail ( $1 \mathrm{ml}$ of ketamine, $0.05 \mathrm{ml}$ xylazine $/ \mathrm{kg}$ body weight). Deep anesthesia throughout surgery was maintained via additional doses of the solution administered at regular intervals. Rats were given postoperative analgesics (Rimadyl, $4.4 \mathrm{mg} / \mathrm{kg}$ ) and antibiotics (Pro-Pen-G, $150,000 \mathrm{U} / \mathrm{kg}$ ) at $24 \mathrm{~h}$ intervals for $3 \mathrm{~d}$ after surgery.

We placed the anesthetized rat into a stereotaxic apparatus, cleaning the scalp with iodine and ethanol, and excising the scalp to expose the skull. We then drilled small craniotomies over the location of GC (anteroposterior $+1.4 \mathrm{~mm}$ from bregma; mediolateral $\pm 5 \mathrm{~mm}$ from bregma; Paxinos and Watson, 2007) and gently removed the meningeal tissue covering the brain. Rats used in the electrophysiology experiments were implanted with 1 (unilateral) or 2 (bilateral) multiwire electrode bundles (25 $\mu \mathrm{m}$ formvar-coated nichrome wires, 16 wires per bundle). Rats used in optogenetic experiments were bilaterally implanted with custom-built optical fiber assemblies (a multimode fiber, 0.22 numerical aperture, 200 $\mu \mathrm{m}$ core, inserted through a $2.5 \mathrm{~mm}$ multimode stainless steel ferrule, THORLABS). Electrode bundles and optical fibers were lowered to 4.7 $\mathrm{mm}$ ventral to the surface of the brain, corresponding to the depth of GC.

After implanting the electrode bundles or the optical fibers, we implanted intraoral cannulae (IOCs) bilaterally into cheeks, and a single bipolar electromyography (EMG) electrode under the chin. Each IOC consisted of a hollow polyethylene tube inserted beneath the temporalis muscle terminating immediately anterolateral to the first maxillary molar (Grill and Norgren, 1978a; Travers and Norgren, 1986; Katz et al., 2001). The EMG electrode (manufactured in-house using PFA-coated stainless steel wire from A-M Systems and connectors from PlasticsOne) was placed in the belly of the left anterior digastric muscle; one end of the electrode was tied to a suture needle, which was then inserted into the muscle, such that the electrode could be pulled into the desired position (for details on the procedure, see Loeb and Gans, 1986; Travers and Norgren, 1986; Dinardo and Travers, 1994). The electrode wire was trimmed and held in place with Vetbond Tissue Adhesive (3M).

The full set of hardware, including electrode bundles, optical fibers, IOCs, and EMG electrodes, was stabilized and cemented in place using dental acrylic bound to screws embedded in the skull.

Histology. Before tissue removal, we deeply anesthetized each rat with an overdose of the ketamine/xylazine solution. We then perfused the animal through the heart with $10 \%$ formalin, and extracted the brain. Coronal brain slices $(50 \mu \mathrm{m})$ were mounted and stained with either cresyl violet (Sigma-Aldrich) or NeuroTrace (Life Technologies) to enable visualization of the neural architecture surrounding the electrode tracks and optical fibers. To monitor the expression of ArchT, slices were labeled with an anti-GFP primary antibody (catalog \#A-11122, Life Technologies) and an Alexa Fluor-488-conjugated secondary antibody (catalog \#A-21206, Life Technologies). Processed brain slices were interpreted (i.e., electrode and fiber tips localized) in reference to a standard rat brain atlas (Paxinos and Watson, 2007). Rats were rejected from analysis if placements were not centered on GC, and if fluorescence was not high.

Habituation. Following recovery from implantation surgery, we habituated each rat to the behavioral chamber for 2 consecutive days before the start of the experiments themselves. During these daily 30 min sessions, we attached the recording cables, fiber optic cables, and fluid delivery apparatus to the hardware on the head of the animal, and infused 60 pulses $(2 \mathrm{pulses} / \mathrm{min})$ of distilled water $(35 \mu \mathrm{l} / \mathrm{pulse})$ into the oral cavity of the animal through the IOC. On the second habituation day, the rat was placed on a mild water restriction schedule $(\sim 4.2 \mathrm{ml}$ of water in 
the behavioral chamber, followed by $15 \mathrm{ml}$ of water in the home cage). This schedule was maintained throughout the duration of the study ( $\sim 5-10 \mathrm{~d} /$ animal).

Presentation of taste stimuli. Since we wished to evoke highly distinct, palatability-related orofacial behaviors, only two highly valenced taste stimuli, palatable sucrose (300 and $30 \mathrm{~mm}$ [strong sucrose (sS) and dilute sucrose $(\mathrm{dS})$ ] and aversive quinine [ 1 and $0.1 \mathrm{~mm}$ strong quinine (sQ) and dilute quinine (dQ)], each dissolved in distilled water, were used for the taste experiments; the two dilute taste solutions, which evoked relatively little in the way of palatability-related taste behaviors, were used to enable analysis of palatability-related firing (see below). The fluid delivery apparatus consisted of a set of pressurized glass cylinders (one for each taste solution) connected to a sequence of plastic tubes of decreasing diameter that ultimately threads through the IOC. A solenoid valve controlled fluid exodus from each glass cylinder. A single taste delivery deposited $\sim 35 \mu \mathrm{l}$ of one of the four solutions onto the tongue of the rat. Tastants were presented in pseudo-randomized order; the elapsed time between each delivery was generated from an exponential distribution (mean, $20 \mathrm{~s}$; upper bound, $15 \mathrm{~s}$; lower bound, $30 \mathrm{~s}$ ). Each tastant was presented 30 times, for a total of 120 separate taste deliveries per experimental session.

Animals were free to move about in the behavioral chamber during each 30 min experiment. Only one experiment was run per animal per day. Between days, the electrode bundles were driven $0.075 \mathrm{~mm}$ ventrally, deeper into GC, to ensure that we obtained fresh units for each session.

Cue experiments. We applied two taste delivery paradigms in this study: "no-cue" and "cue." Cue experiments, which were included to test whether the appearance of palatability coding followed changes in behavioral latency, differed from no-cue experiments in only one respect: a 4 $\mathrm{kHz}$ auditory tone of constant amplitude was played for $1 \mathrm{~s}$ preceding each $s Q$ delivery. The no-cue experiment was run for 2-3 consecutive days, followed generally by $1-2 \mathrm{~d}$ of the cue experiment. For the animals in which the cue experiment was run for $2 \mathrm{~d}$, data were pooled across both days, because the change in the latency of gaping was linear and continued for two full sessions, such that the change between the first and last quarter of the trials did not differ significantly between the first and second day $\left(z_{(15)}=-1.01, p=0.32\right.$, Wilcoxon rank sum test).

Optogenetic inactivation. To test whether behavior depends on an intact GC, $532 \mathrm{~nm}$ laser light (Shanghai Dream Lasers Technology) was coupled to the implanted optical fibers using customized FC/PC patch cables (THORLABS), and the power was adjusted to produce a reading of 40 or $10 \mathrm{~mW}$ at the tip of the fiber. For the optogenetic experiments, half of the taste deliveries ( 60 deliveries, 15 deliveries/tastant) were randomly selected to include GC inactivation. For these deliveries, the laser was turned on for $2.5 \mathrm{~s}$ following the opening of the solenoid valve.

Conditioned taste aversion. To confirm the effectiveness with which we were able to optogenetically inactivate GC, we tested a separate set of infected and control rats on a conditioned taste aversion (CTA) task, with successful CTA learning being dependent on GC (Dunn and Everitt, 1988; Gallo et al., 1992; Schafe and Bernstein, 1998; Roman et al., 2006). Animals were first adapted to obtaining pulses of distilled water through the IOC by inserting their nose into a small port equipped with an infrared beam $(60 \mu \mathrm{l} /$ poke; 100 pokes; $3 \mathrm{~s}$ enforced delay between each poke; total session length, $<30 \mathrm{~min}$ ). After $2 \mathrm{~d}$ of adaptation, distilled water was replaced with a $0.15 \%$ saccharin solution, and the laser was turned on for $2.5 \mathrm{~s}$ following each saccharin delivery (i.e., training day). Once the animal had consumed $6 \mathrm{ml}$ of the solution, we induced gastric malaise by injecting 0.6 M lithium chloride ( $1 \%$ body weight, dissolved in distilled water, similar to concentrations and amounts used in other studies; Nachman and Ashe, 1973; Misanin and Hinderliter, 1994; Maier et al., 2014 ) into the intraperitoneal cavity. The following day (testing day), we returned the animal to the behavioral chamber, and recorded the number of times the animal poked for saccharin within a $30 \mathrm{~min}$ period. Control animals were not injected with virus, but received light only. Some animals also received 30 passive deliveries of $0.1 \%$ saccharin through the IOC, and the EMG signal was analyzed to determine the number of gapes per delivery (see below).
Acquisition of EMG data. Voltage signals from the bipolar electrode embedded in the anterior digastric muscle were passed through a General Purpose AC Preamplifier (model P55, Grass Technologies) and sampled at $1000 \mathrm{kHz}$. The signal was filtered off-line using a fourth-order Butterworth bandpass filter (300-500 Hz; Travers and Norgren, 1986), and the filtered result was rectified. Occasionally, minimal EMG activity was observed following the opening of the solenoid valve; as this was possibly due to the presence of air bubbles in the fluid delivery apparatus, such trials were eliminated from further analysis.

Gape detection algorithm. Gapes were identified from EMG responses using the following two-step process: (1) we first identified all mouth movements produced in the $2.5 \mathrm{~s}$ immediately following taste delivery; and (2) then used a quadratic classifier to label each movement as a "gape" or "nongape."

To identify individual mouth movements, we extracted the envelope of the filtered, rectified EMG signal using a $15 \mathrm{~Hz}$ low-pass fourth-order Butterworth filter (MathWorks), sufficient for capturing different types of taste-related mouth movements (all of which exist at frequencies $<10$ $\mathrm{Hz}$, with gapes occupying the lower end of that spectrum; Grill and Norgren, 1978); Fig. $1 A$ provides evidence that the filter dealt linearly with low frequencies in the data. Each local peak in the envelope was deemed a mouth movement. The onset and offset of each movement were defined as the time points at which the magnitude of the envelope exceeded and returned to the mean value of the envelope from the baseline period ( -1.5 and $0 \mathrm{~s}$ relative to taste delivery, respectively).

We used quadratic discriminant analysis to label each mouth movement (save some very early, nondistinctive movements; Fig. 1; see Results) as a gape or a nongape, quantifying movements for the analysis on the basis of two features known to distinguish gapes from intraoral licks and lateral tongue movements (Travers and Norgren, 1986), namely, movement duration (the time between movement onset and offset) and movement frequency (the reciprocal of the time between the peak of a given movement and the peak of the most distal adjacent movement). To train the classifier, we obtained a corpus of 30 frames/s video recordings (HD Pro Webcam C920, Logitech) of 1169 separate mouth movements $(N=5$ animals) produced following deliveries of $s \mathrm{Q}, 437$ of which were visually determined to be gapes by a blind rater (see Fig. $3 A$, blue dots).

We evaluated the classifier by jackknife-excluding data from each animal in turn, fitting the classifier on the data from the four remaining animals, and evaluating the resulting classifier on the excluded dataset. The classifier achieved an average $d^{\prime}$ value of 1.5 on the held-out data (see Fig. $3 B$ ), corresponding to an accuracy of $\sim 80 \%$. Additional validation of the classifier is shown in Figure $3 C$, which plots the average number of gapes detected by the algorithm following the delivery of each of the four taste solutions. As expected, the most aversive tastant, $s Q$, elicited the greatest number of gapes, nearly double that of the second-most aversive tastant, dQ.

Acquisition of electrophysiological data. Voltage signals from ensembles of GC neurons were sampled at $40 \mathrm{kHz}$, amplified, filtered, and saved to hard drive (using hardware from Plexon). From these raw voltage signals, we retained all waveforms whose amplitude was at least three times larger than the noise, and sorted the resulting waveforms into distinct units using three-dimensional cluster-cutting techniques (Offline Sorter, Plexon). Sorted waveform records were digitized at $1 \mathrm{kHz}$. A total of 161 and 133 single units were obtained for the no-cue and cue experiments.

Analysis of time course of palatability-related responding. For each neuron recorded in the no-cue experiments, we used a moving window analysis to identify the times at which the responses of the neuron were palatability related. We defined "palatability relatedness" as we have previously (Piette et al., 2012; Sadacca et al., 2012; Maier and Katz, 2013), as follows: the extent to which the magnitude of the responses of the neuron to each of the four taste stimuli reflects (i.e., correlates with) the palatability ordering of the stimuli. For a given neuron, we first binned the spike train produced by the neuron following each taste delivery (span, 0 to $2.75 \mathrm{~s}$ ) using partially overlapping time windows (window size, $1 \mathrm{~s}$; step size, $0.1 \mathrm{~s}$ ). We then 


\section{A Quinine response}

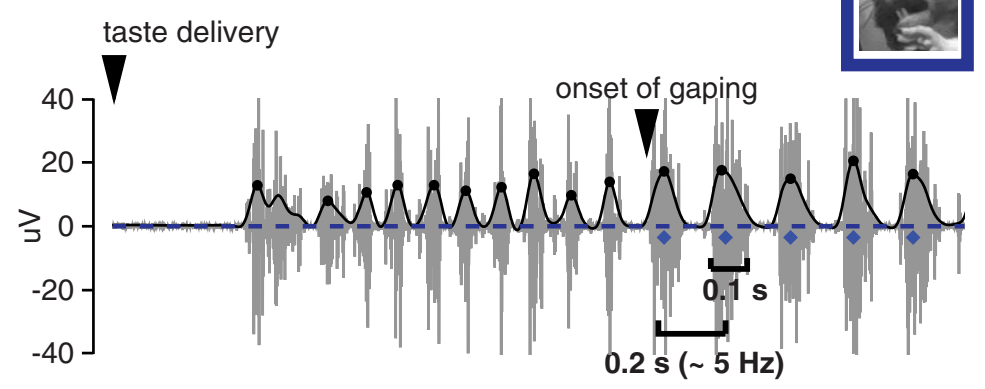

B Sucrose response

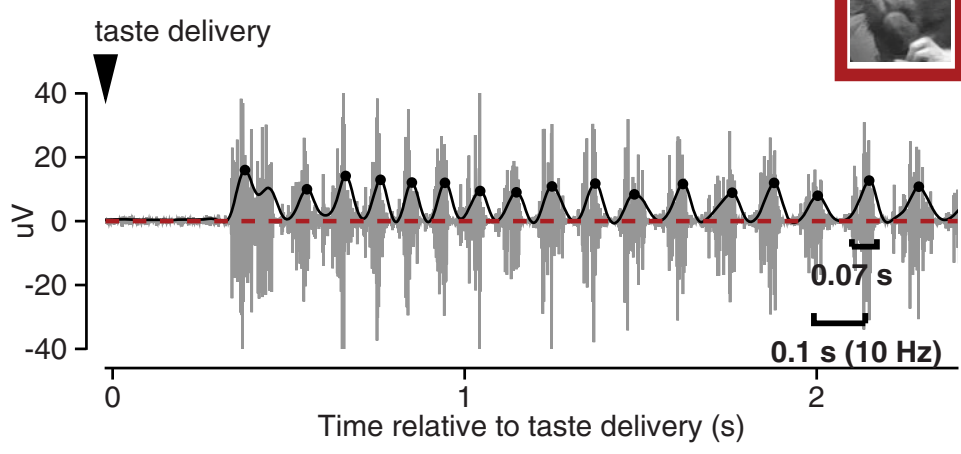

Figure 1. Jaw EMG activity to aversive versus pleasurable taste stimuli. $\boldsymbol{A}$, The gray trace plots the EMG activity in the jaw of a rat following a single delivery of $\mathrm{Q} Q$. The overlaid thick line is the output of rectifying and low-pass filtering the data for the calculation of jaw movement peaks (circles), gapes (diamonds), and the time at which the first gape appears; a video frame from during that first gape is shown in the inset. $\boldsymbol{B}$, Same as $\boldsymbol{A}$, but for sS; note the absence of gapes. The video frame is taken from during the (putative) first LTM. Note that palatability-related responses are preceded by a period during which the EMG signal is flat (i.e., the basic response latency) and a period during which nondistinctive licks occur (taste processing).

computed the rank correlation between the spike count in each window and the palatability ranking of the corresponding taste $(\mathrm{sS}>$ $\mathrm{dS}>\mathrm{dQ}>\mathrm{sQ}$ ). $t$ Tests were used to conservatively evaluate the statistical significance of the correlation coefficient obtained for each time window (required significance level, $p<0.005$ ). To further minimize the effect of false-positive results upon our final analysis, we included only stretches of palatability-related firing consisting of three or more consecutive time windows. Instead, using a threshold of two or one consecutive windows did not alter our general conclusions, but three consecutive windows were used because this effectively removed all evidence of artifactual significance in the prestimulus period.

To analyze the palatability relatedness of EMG responses, we used a method identical to the one applied to the neural responses, but, instead of the spike count in each time window, we used the mean EMG power between 4 and $6 \mathrm{~Hz}$. EMG power was computed using a multitaper spectral estimation method (Chronux.org; Babadi and Brown, 2014).

Time course of cued taste distinguishability. To measure how experience with the cue changes one particular taste response in GC, we first divided the data from each cue experiment in half, with one half containing the responses of the neuron to the first 15 deliveries of each tastant (a total of 60 separate taste deliveries), and the other, the last 15 deliveries. We analyzed the neural data from each half separately using a moving window method similar to the one described above, except that instead of computing the rank correlation with taste palatability, we used a Wilcoxon rank sum test to compare the magnitude of responses to $s Q$ with those to the three other tastants (using $p<0.005$ as the threshold for significance).
Perigape time histograms. For each neuron, we calculated two perigape time histograms (PGTHs), one to quantify changes in firing around the onset of "first gape," and another to assess firing to "later gapes." The term first gape collectively refers to the earliest occurring gape following each taste delivery, while the term later gapes describes all subsequent gapes. Thus, 30 separate taste deliveries can yield at most 30 first gapes, but typically many more later gapes. PGTHs were calculated exclusively for responses to $\mathrm{sQ}$, as it was the only stimulus that reliably elicited gapes.

To calculate a PGTH, we averaged the -0.08 to 0.04 s portion of the spike train surrounding each first gape or later gape. We then subtracted this original response by the mean response produced after shuffling the order of the spike trains (100 permutations per neuron), a procedure that disassociates the neural activity from the behavior produced on the same trial. Subtracting the shuffled response from the original response allows us to isolate the portion of the original response specifically related to the onset of the gape, regardless of the direction of that response. A neuron was determined to have a significant gapeassociated change in firing rate if the peak of its original response was $>95 \%$ of the peaks from its shuffled responses.

Statistical details. Standard parametric and (in the case of non-normal data) nonparametric statistics are used throughout to compare differences in central tendencies and distributions. Means are reported with SEMs (the variance measurement that is directly used in significance testing). When the data involve Bernoulli distributions (Fig. $2 D$; see also Fig. $5 C, D$ ), the SEM of the probability of success is calculated as $\operatorname{sqrt}(p *$ $(1-p) / n)$, where $p$ is the average probability of success, and $n$ is the number of observations.

\section{Results}

Behavior-related activity appears in GC before it appears in EMG

We first studied the relationship between GC activity and tasterelated mouth movements using a no-cue taste delivery paradigm (see Materials and Methods). For this paradigm, the rat could anticipate neither the identity nor the timing of the impending tastant. Experimental sessions consisted of 120 tastant deliveries, each pseudorandomly selected from a battery of four options, two of which were aversive- $-\mathrm{sQ}(1 \mathrm{~mm})$ and $\mathrm{dQ}(0.1 \mathrm{~mm})$ - and two of which were pleasant- $\mathrm{dS}(300 \mathrm{~mm})$ and $\mathrm{sS}(30 \mathrm{~mm})$.

Figure 1 shows two representative examples of EMG activity recorded from the anterior digastric muscle, one following presentation of aversive sQ (Fig. $1 A$, top), and the other following presentation of pleasant $\mathrm{sS}$ (Fig. $1 B$, bottom); Figure $1 A$ includes the output of rectification and filtering of the signal. Obvious in these examples is the standard behavioral reaction time (Travers and Norgren, 1986; Fontanini and Katz, 2006), the period during which the EMG response appears flat, after which rats produce bouts of nonspecific (i.e., identical for all tastes) $6-7 \mathrm{~Hz}$ licks. Following this bout, the EMG signal becomes dominated by mouth movements reflecting the palatability of the taste, which is the degree to which the tastant is pleasant or aversive (Berridge et al., 1984; Travers and Norgren, 1986; Spector et al., 1988). Move- 
A

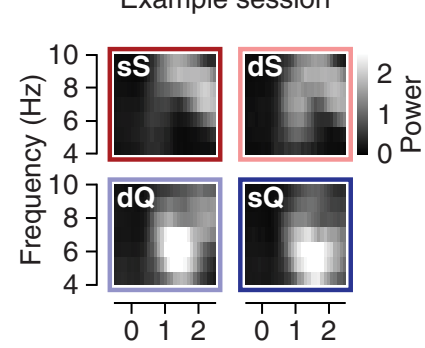

C

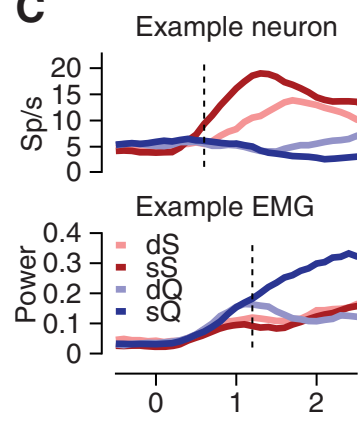

B

Session average

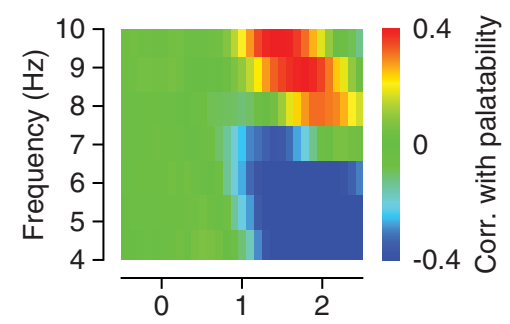

D

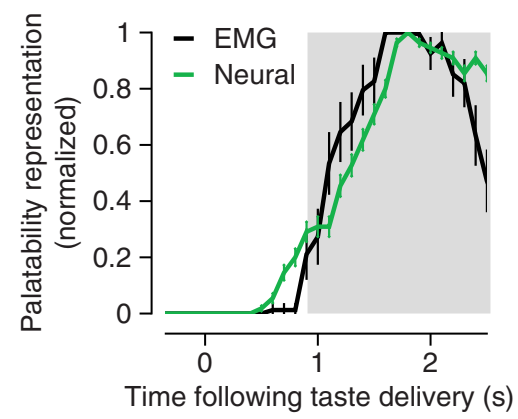

Session standard error

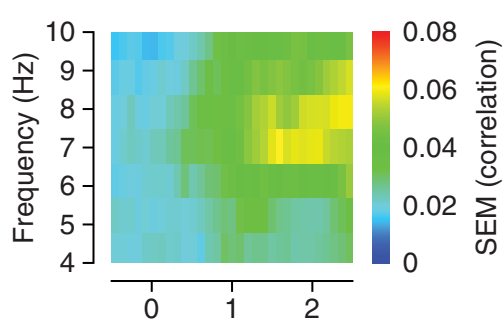

Figure 2. Comparison of palatability representation in $\mathrm{GC}$ and EMG activity. $\boldsymbol{A}$, Each intensity plot shows the frequency content ( $y$-axis) of the mean EMG response as a function of time $(x$-axis) following delivery of one of the four taste stimuli (data averaged across 15 animals); brighter pixels indicate higher power. $\boldsymbol{B}$, The left heat map depicts the rank correlation between taste palatability and EMG power (data averaged across 15 animals) for frequencies between 4 and $10 \mathrm{~Hz}$ across poststimulus time. Statistically significant correlations are plotted in blue or red (blue, negative; red, positive), with stronger color intensities indicating higher correlations. The right map shows the SE across sessions for each point in the correlation plot. C, Comparison of concurrently recorded neural and EMG responses following taste delivery. Both types of responses were smoothed with a $1 \mathrm{~s}$ rectangular window. Top, Each line represents the mean firing rate ( $y$-axis) through poststimulus time ( $x$-axis) of a representative $\mathrm{GC}$ neuron to one of the four taste stimuli: $300 \mathrm{~mm}, \mathrm{SS}$ (dark red); $30 \mathrm{~mm}$, $\mathrm{dS}$ (light red); $0.1 \mathrm{~mm}, \mathrm{dQ}$ (light blue); and $1 \mathrm{~mm}, \mathrm{SQ}$ (dark blue). The vertical dashed line indicates the earliest time at which the responses of the neuron were significantly correlated with taste palatability. Bottom, Same as above, but for the mean EMG power in the $4-6 \mathrm{~Hz}$ range. $D$, The fraction ( $y$-axis) of GC neurons ( $n=161$; green line) and paired EMG ( $n=20$; black line) producing palatability-related responses as a function of time ( $x$-axis) following taste delivery (error bars $=S E M)$. The left edge of the gray box is aligned with the average onset time of the first gape following deliveries of $\mathrm{s} Q$, as determined by the gape detection algorithm.

ment peaks (circles), gapes (diamonds), and the onset of gaping are noted in the panels.

These EMG recordings can be reliably used to distinguish quinine-induced gapes, which signal aversion (Fig. 1A), from other types of taste-related mouth movements, such as nonspecific licks or LTMs (Grill and Norgren, 1978a; Travers and Norgren, 1986; Dinardo and Travers, 1994; Fig. 1B). Gapes appear as long EMG bursts (mean duration, $0.1 \mathrm{~s}$ ) with an interburst interval of $\sim 0.2 \mathrm{~s}$; nonspecific licks, in contrast, have both a shorter duration and interburst interval (for description and validation of the gape detection algorithm, see Materials and Methods), and LTMs have an even shorter interburst interval (see the response to $\mathrm{sS}$ ) - the difference between LTMs and simple licks are difficult to reliably distinguish, however, and are not examined further.

Again, both aversive and pleasant tastants initially elicit a rhythmic sequence of nonspecific licks. If the tastant is aversive, the licks typically give way to a bout of gapes. The shift from licking to gaping is abrupt and complete-for the example sQ trial in Figure 1, the transition occurred $\sim 1.8 \mathrm{~s}$ after taste delivery (note that this trial was chosen for visual inspection specifically for the lengthy bout of nonspecific licks before the switch to gapes; on most trials, this transition occurred earlier; see below). For sS and other pleasant stimuli, a similarly abrupt transition occurs between nonspecific licks and mouth movements that indicate pleasure, such as LTMs (Grill and Norgren, 1978a), although this transition is not as easy to observe in anterior digastric activity as the transition to gaping in the EMG signal in
Figure $1 A$, because the anterior digastric muscle drives jaw movements and not tongue movements.

Note that a short-latency EMG burst can be observed to occur in both Figure 1 responses. These bursts, which occurred at low rates (one such burst in $\sim 20 \%$ of trials), were likely reactive mouth movements in response to intraoral delivery; analysis revealed that they were observed with approximately equal frequency across all four taste stimuli; $F_{(19)}=0.69, p=0.81$, by repeated-measures one-way ANOVA) and that thus, like the often described nonspecific licks that follow, these bursts were unrelated to tastant palatability. They were therefore excluded from further analysis.

The differences in frequency among different orofacial behaviors, as illustrated in the example traces in Figure 1, suggest that the spectral content of the EMG signal may be distinct for aversive and pleasant tastants. This suggestion was borne out in quantitative analysis: because rats gape to aversive tastants, the EMG spectrograms for dQ and sQ (Fig. 2A, bottom panels) have more power between 4 and $6 \mathrm{~Hz}$, the frequency of the gape rhythm. In contrast, the EMG spectrograms for $\mathrm{dS}$ and $\mathrm{sS}$ are denser between 8 and $10 \mathrm{~Hz}$ (Fig. 2A, top panels), because rats produce LTMs instead of gapes when presented with pleasant tastants. These spectral differences between aversive and pleasant tastants are summarized, across all rats and trials, in Figure $2 B(n=20)$, which plots the rank correlation between taste palatability (from most to least palatability: $\mathrm{sS}>\mathrm{dS}>\mathrm{dQ}>\mathrm{sQ}$ ) and power in each frequency band as a function of time following taste delivery. The correlations in the $4-6$ and $8-10 \mathrm{~Hz}$ bands are (as expected) 


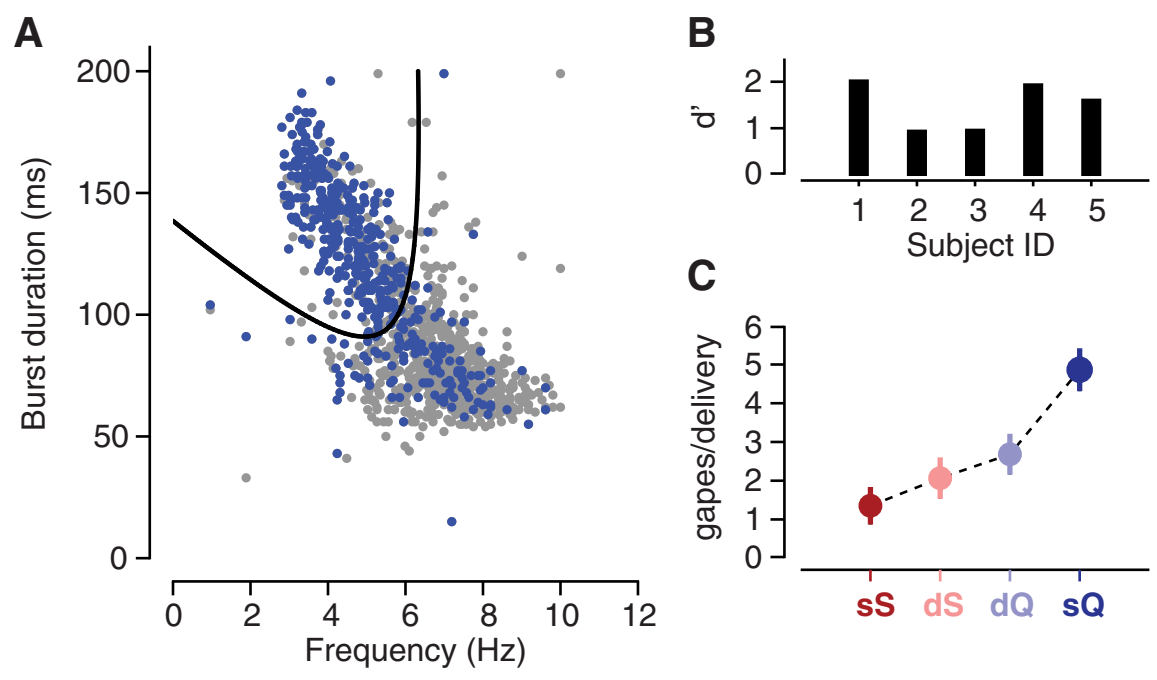

Figure 3. A quadratic classifier for distinguishing gapes from nongapes. A, A scatter plot of duration vs frequency for 1169 separate mouth movements (aggregated across five animals). Movements visually determined to be gapes are colored in blue; nongapes, gray. The thick black curve represents the decision boundary of the classifier; each movement was assigned as a gape or nongape depending on its location above or below the curve. $\boldsymbol{B}$, The results of a cross-validation analysis: each bar corresponds to the performance of the classifier on data from a separate animal in the training set. Larger $d^{\prime}$ values indicate better classifier performance. $C$, Average number of gapes detected in the EMG activity across the 2.5 s period immediately following taste delivery. Error bars denote the SEM across animals $(N=5)$.

opposite in sign, and both diverge from zero $\sim 1 \mathrm{~s}$ following taste delivery, corresponding to the approximate time at which palatability-related behaviors have been reported to appear (Travers and Norgren, 1986).

If $\mathrm{GC}$ is to be considered to be potentially involved in mediating the shift from nonspecific licks to palatability-related mouth movements, then palatability-related information must, minimally, emerge earlier in GC responses than in EMG responses. To test this prediction, we tracked the time course of palatability-related information in the neural and EMG signals, using standard moving-window correlational analyses (see Materials and Methods; Katz et al., 2001; Piette et al., 2012; Sadacca et al., 2012). In brief, we defined the palatability relatedness of a signal as the extent to which the magnitude of the signal increases (or decreases) with taste palatability. For each GC neuron, we computed the rank correlation between the palatability of every tastant delivered in the experiment (palatability ranking: $s S>$ $\mathrm{dS}>\mathrm{dQ}>\mathrm{sQ}$ ) and the number of spikes emitted by the neuron, performing this analysis independently for successive time windows following the delivery of said tastant. For the EMG responses, we performed the identical analysis, but replaced firing rate with EMG power between 4 and $6 \mathrm{~Hz}$, the frequency range of the gape rhythm (essentially identical results were obtained when the analysis was restricted to power in the frequency range of LTMs).

This analysis revealed that palatability-related information appears earlier in GC responses than in EMG activity. Figure $2 C$ shows an example of this phenomenon at the single-cell level. The top panel in Figure $2 C$ plots the average firing rate of an example neuron to each of the four taste stimuli, and the bottom panel plots $4-6 \mathrm{~Hz}$ power in concurrently recorded EMG responses. The response of this particular neuron to the most pleasant tastant (sS), illustrated by the dark red trace in Figure $2 C$, rose rapidly and became distinct from responses to the aversive tastants (light and dark blue traces) well before $1 \mathrm{~s}$. In contrast, the four EMG responses did not begin to clearly diverge until much later, when the response for the aversive tastants (blue traces) began to outstrip the responses to dilute and strong sucrose. The neural responses became significantly correlated with taste palatability $\sim 0.6$ s following stimulus delivery (Fig. $2 C$, top panel, dashed vertical line), compared with $1.2 \mathrm{~s}$ for the concurrently recorded EMG responses (Fig. 2C, bottom panel, dashed vertical line).

We performed a neuron-by-neuron analysis (restricting that analysis to neurons for which the correlation with taste palatability exceeded $p<0.005$ for at least three or more consecutive $1 \mathrm{~s}$ time windows) of the phenomenon described in Figure $2 C$ (i.e., comparing the onset of palatability in the firing of each neuron to the onset of palatability in the concurrently acquired EMG response). In $22 \%$ of the 78 neurons $(n=17)$, palatability appeared in spiking responses before appearing in EMG; in 10\% of the neurons $(n=8)$, the palatability signals emerged with similar timing in brain and behavior, and in $68 \%$ of the neurons $(n=53)$ neural evidence of palatability lagged the EMG.

Finally, Figure $2 D$ summarizes the results of palatability-electrophysiology correlations for the full set of no-cue experiments ( $N=11$ animals, 20 sessions). We calculated the fraction of neurons (of 161 neurons) whose responses encoded palatabilityrelated information as a function of time following taste delivery and did the same for the concurrently recorded EMG responses $(n=20)$. Both functions were normalized to their maximal values to facilitate comparison of their time courses (black and green lines), which allows us to show that, consistent with earlier studies (Fontanini and Katz, 2006; Piette et al., 2012; Sadacca et al., 2012; Maier and Katz, 2013), correlations with palatability begin to emerge in the GC population at $0.5 \mathrm{~s}$ (Fig. $2 D$, the green line diverges from zero at this time). Palatability emerged in GC firing $\sim 0.3$ s earlier than seen in the jaw movements of the animal.

Of course, the moving window analysis only approximately captures what are in reality sudden changes (e.g., the fact that the first gape appears at a particular moment, and the fact that neural firing rates to tastes change very suddenly; Jones et al., 2007; Moran and Katz, 2014). For the remainder of this article, we therefore focus specifically on the timing of gapes (limiting our analysis to gapes simply because they are the easier of the palatability-specific behaviors to observe with digastric EMG; see Fig. $1 B, C)$. To pinpoint the onset time of gapes, we trained a supervised learning algorithm to classify each EMG burst as a gape or nongape based on known distinctive properties of the burst (Fig. 3). Using this classification algorithm, we found that the average ( \pm SEM) latency of the first sQ-elicited gaping bout was $1.00 \pm 0.04 \mathrm{~s}$; the average time period between first and last gapes in a bout is indicated by the gray shaded area in Figure $2 D$. The latency to first gape, which is similar in magnitude to those reported in earlier reports (Travers and Norgren, 1986), trails the appearance of palatability-related firing in GC (green trace) by nearly $0.5 \mathrm{~s}$. It also lags slightly behind the onset of palatability-related information in the EMG responses (black trace), likely reflecting the time windows used to generate the latter. 
Cortical single-neuron firing is modulated before the onset of gaping in individual trials

While the above results suggest that GC activity is well timed to play a role in the selection of behavior, more thoroughly testing a hypothesized link between GC activity and the onset of gaping requires that we go beyond these general correlations to show that, on a trial-by-trial basis, the transition from nonspecific licks to gapes is closely associated with GC firing (in a manner that can be more easily evaluated for statistical significance). We have previously shown efferent sensory signal related to nonspecific licking (Katz et al., 2001), but these signals are highly noisy and difficult to reliably detect in single trials.

We found that $\sim 14 \%$ of assayed GC neurons (23 of 161 neurons) exhibited significant $(p<0.01)$ changes in firing rate in the period immediately preceding and/or succeeding the time of the earliest gape produced following taste delivery (first gape; see Materials and Methods), 16 times the number expected by chance. Examples of these neurons are shown in Figure $4 A$. Each subpanel of Figure $4 A$ plots the PGTHs for one neuron; the black traces represent the PGTH measured for the first gape, and the gray traces, later gapes. All of these responses of the neurons included a clear (and significant) peak before time 0 (dashed vertical line), suggesting that the firing rate modulation preceded the moment of gape onset, a finding that was representative of the population (Fig. $4 B$ ). In contrast, neural modulations surrounding later gapes are either nonexistent or muted. These results suggest that for a subset of GC neurons, a change in firing is tightly linked to the transition from nonspecific licks to gapes, and further suggest that GC firing is not generally predictive of the production of individual gapes per se (in that it is only modulated before initial gapes in a bout, and not later gapes).

The population $(N=161)$ average recapitulated and confirmed the effects observed in the single-neuron examples, despite the inclusion of nonresponsive neurons; the peak modulation of GC firing in relation to first gapes (black trace) was several times larger than that for later gapes (Fig. $4 C$, gray trace). GC firing rates start to deviate from baseline (see Materials and Methods) during the time leading up to the emission of the first gape. Firing rates before the first gape became different from baseline, and from activity preceding other gapes, $40 \mathrm{~ms}$ before the onset of gaping $(p<0.05 ; t$ statistic $=2.0$, paired $t$ test $)$. Furthermore, firing rates changed across the $40 \mathrm{~ms}$ preceding the first gape, whereas there was no significant modulation of GC activity preceding later gapes $(p=0.86, t$ statistic $=-0.17$, paired $t$ test). This lack of modulation preceding later gapes was similar when the comparison dataset was restricted to a randomly selected subset of later gapes $(p=0.84, t$ statistic $=-0.20$, paired $t$ test), a control for any computational artifacts that may have resulted from the greater preponderance of later gapes.

Note that for the preceding analysis, we rectified the PGTHs of individual neurons before computing the population average to prevent neurons with an increase in firing rate (positive peak) from canceling out neurons with a decrease in firing rate (nega-

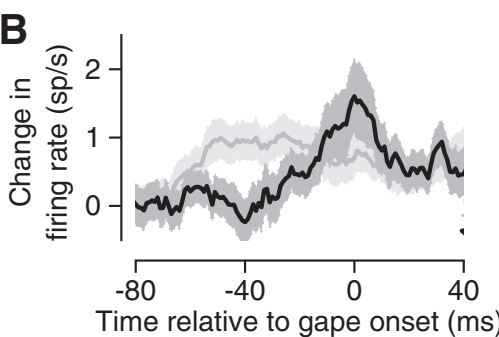

\section{C}

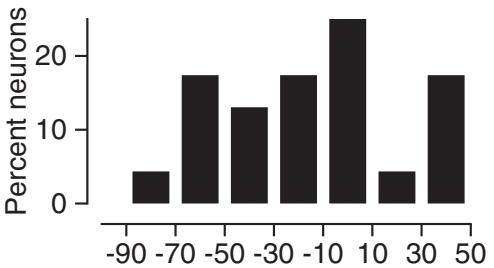

Time of peak relative to gape onset

Figure 4. Firing rate modulations in $\mathrm{GC}$ before and during the production of individual gapes. $\boldsymbol{A}$, Each subpanel shows the gape-triggered change in firing rate ( $y$-axis) for a different $\mathrm{GC}$ neuron. The black (gray) trace depicts the neural response triggered on the first (later) gapes produced by the animal following infusions of $s Q ; 0$ on the $x$-axis represents the onset of an individual $(N=161)$; responses of individual neurons were inverted when necessary so as to treat inhibitory and excitatory changes similarly. Error bands in $\boldsymbol{A}$ and $\boldsymbol{B}$ indicate the SEM.

tive peak). We also performed a neuron-by-neuron analysis of the actual direction of firing rate modulations, and found that the majority of GC neurons [123 of 161 neurons (76\%)] increased their firing rate with the onset of the first gape. A positive peak was even more prevalent among neurons selected for statistically significant $(p<0.01)$ changes in firing rate [22 of 23 neurons $(96 \%)]$.

\section{Reducing quinine gape latency via expectation}

correspondingly reduces the latency of quinine GC responses

The preceding analyses provide phenomenological evidence supporting the suggestion that GC responses could play a role in the selection of behavior. A more compelling case for this hypothesis, however, requires demonstration that perturbation of behavior has predictable implications for GC taste responses, and vice versa.

We performed experiments to test both predictions. First, we manipulated the time at which gapes appear, and tested whether this manipulation similarly shifts the timing of GC neural responses. We altered the latency of gaping via a set of cue experiments, which were identical to the no-cue experiments, except for the addition of a $4 \mathrm{kHz}$ tone that was selectively played for $1 \mathrm{~s}$ immediately before each sQ delivery.

We found that over the course of a cue experiment, rats come to make use of the predictive tone by gaping earlier in response to the ensuing sQ delivery. When we split every session of the cue experiment into two halves (each of which consisted of 15 deliveries of sQ and 15 each of the three other tastants), the latency of the first gape to sQ decreased by $0.15 \pm 0.06 \mathrm{~s}$ between the first and second halves of the experiment (Fig. 5A). This change in gape latency was specific to the cued tastant $s Q$ (and thus did not represent a generalized shift in the timing of taste-related orofacial responses) and was significantly different from the (essential lack of) change in gape latency to $\mathrm{QQ}$ observed in no-cue experiments $\left(p=0.03, z_{(25)}=-2.17\right.$, Wilcoxon rank sum test), demonstrating that the decrease in gape latency did not represent a 
A

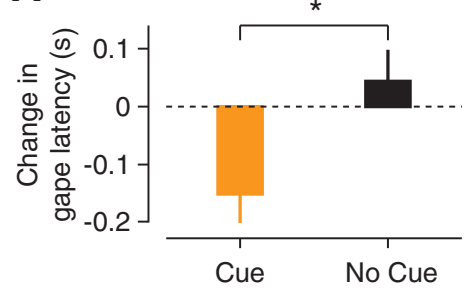

B

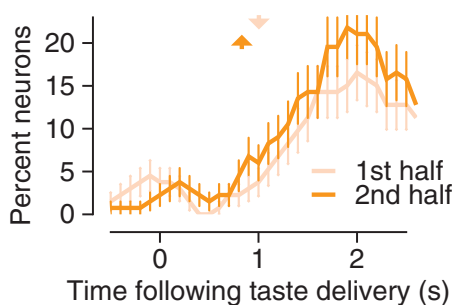

C

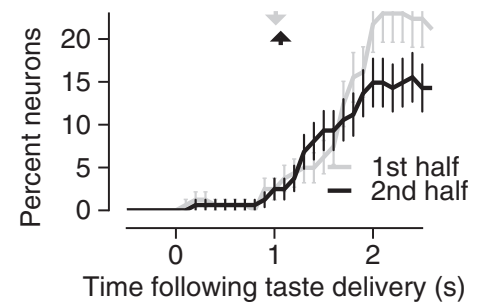

Figure 5. Cue-related changes in the timing of behavioral and neural responses. $A$, Difference in the latency of the first gape ( $y$-axis) between the first $15 \mathrm{sQ}$ trials and the last $15 \mathrm{~s} Q \mathrm{trial}$, for the cue (orange) and no-cue (black) experiments. Negative values indicate a decrease in gape latency over the course of the experiment. Error bars denote SEM across animals (cue, $N=12 ; n o-c u e, N=$ 15). ${ }^{*} p=0.03 . B$, Each trace represents the percentages of neurons recorded in cue experiments $(N=133)$ that exhibited $s$-selective responses as a function of time following taste delivery: results from the first 60 trials of each cue experiment are shown in light orange, and the last 60 trials, in dark orange. The two vertical dashed lines, colored to match the response traces, correspond to the latency of the first gape averaged across either the first $15 \mathrm{~s} Q$ trials (light orange) or the last $15 \mathrm{~s} Q$ trials (dark orange). $C$, Same as $\boldsymbol{B}$, but for the no-cue experiments ( $n=161)$. Data from the first half of the no-cue experiments are in gray, and from the last half, in black.

general consequence of receiving multiple sQ deliveries. Meanwhile, the onset of nonspecific licks remained stationary over the course of both the cue (average change, $+0.02 \mathrm{~s} ; \mathrm{SEM}, 0.01 \mathrm{~s}$ ) and no-cue experiments (average change, $+0.01 \mathrm{~s}$; SEM, $0.01 \mathrm{~s}$ ), and there was no significant difference between the two behavioral paradigms ( $p=0.23, z=1.19$, Wilcoxon rank sum test). Cuing sQ specifically changes the latency to the first sQ gape.

Furthermore, this cue-induced shift in gape latency was paralleled by a shift in the timing of GC responses (Fig. $5 B$ ). We performed a moving window analysis independently on each half of the cue experiments to determine when GC neurons began to distinguish $\mathrm{sQ}$ from the other tastants (as we only cued one taste, any change would likely not be picked up by our standard palatability correlation analysis, which is an across-taste measure; see Materials and Methods). In brief, a neuron is said to have sQselective responses if the magnitude of its responses to $S Q$ are statistically distinguishable from its responses to the three remaining tastants. For both the first (pale orange) and second (dark orange) halves of the experiment, following tastant delivery, there was a gradual increase in the prevalence of neurons with sQ-selective responses. The onset of the ramp decreased by $\sim 0.2$ $\mathrm{s}$ (from 1.0 to $0.8 \mathrm{~s}$ ) between the first and second halves of the experiment. This change is significantly larger $(p<0.01)$ than what would be expected by randomly partitioning the trials into two groups and performing the same moving window analysis on each group. Taking into account the noise inherent in estimates of latency from binned data, the shift in the latency of sQ selectivity in the neural responses is a good match for the shift in the gape latency (Fig. 5B, reproduced in the vertical dashed lines, colored to match the electrophysiological data).

GC responses recorded during the cue and no-cue experiments differed in two important ways. First, for the no-cue experiments, the time at which sQ-selective responses emerged did not change appreciably over the course of the session-both the black and gray traces in Figure $5 C$ start to rise at about the same time following taste delivery. This result suggests that the decrease in the latency of sQ-selective responses observed in the cue experiments is not simply related to experience with taste stimuli. In addition, experience with the cue led to an $\sim 33 \%$ increase in the percentage of neurons with $\mathrm{sQ}$-selective responses (note that the dark orange line in Fig. $5 B$ lies above the light orange line). In contrast, neurons with sQ-selective responses became scarcer late in the no-cue sessions (Fig. $5 C$, black line, asymptotes are shown below the gray line), perhaps due to habituation.

The present analysis focused on poststimulus neural responses. However, similar to what has been previously reported in the literature (Samuelsen et al., 2012), we also observed cueselective responses in a subset of GC neurons, which are visible as the small bump in the light and dark orange traces in Figure $5 B$, in the time preceding stimulus delivery, and the absence of a similar bump in the data from the no-cue experiments (Fig. $5 C$, black and gray traces). Neurons with cue-selective responses and those with $\mathrm{sQ}$-selective responses comprised two overlapping populations; the proportion of neurons with both types of responses was comparable to what would be expected by chance (data not shown).

\section{Optogenetic inactivation of GC significantly increases the probability of gaping to $1 \mathrm{~mm}$ quinine}

In a complementary set of manipulation studies, we directly assessed whether the production of gapes is impacted by the perturbation of GC neuron firing (i.e., GCx). We bilaterally infused adeno-associated virus containing ArchT, a light-gated optical silencer, into GC, and waited for GC neurons to express high levels of ArchT $(\sim 4$ weeks after the virus infusion; Han et al., 2011). We then performed a set of experiments in which we used green laser light to selectively suppress GC activity coincident with a random half of the taste deliveries (GCx trials). GC activity was not altered for the remaining taste deliveries (light-off trials), which allowed us to perform a within-animal comparison of gape responses with and without intact GC. Finally, we performed "light-only" experiments on noninfected rats to control for the effect of illumination itself on GC firing and taste-related mouth movements.

Before testing the effects of GC inactivation on gaping, we first confirmed the effectiveness of optogenetic inactivation using a CTA protocol in a separate set of rats (see Materials and Methods). CTA is a form of learning that is known to be sensitive to GCx (Dunn and Everitt, 1988; Gallo et al., 1992; Schafe and Bernstein, 1998; Roman et al., 2006), and our experiment confirmed this result. After being conditioned with a saccharin aversion, GC-inactivated animals $(N=10)$ overcome their aversion and exhibited $265 \%$ greater consumption of saccharin $(p=0.03$; rank sum statistic $(15)=84.5$, Wilcoxon rank sum test) compared with the light-only controls (that did not experience GC inactivation, $N=7$ ). Learned aversions were not entirely absent in rats with GC inactivation, but they were greatly diminished, consistent with the suggestion that we are able to optically reduce levels of GC activity.

On a separate, naive set of rats, this same level of GC inactivation led to a small but significant increase in the probability that the animal would gape within $2.5 \mathrm{~s}$ following deliveries of sQ (Fig. 


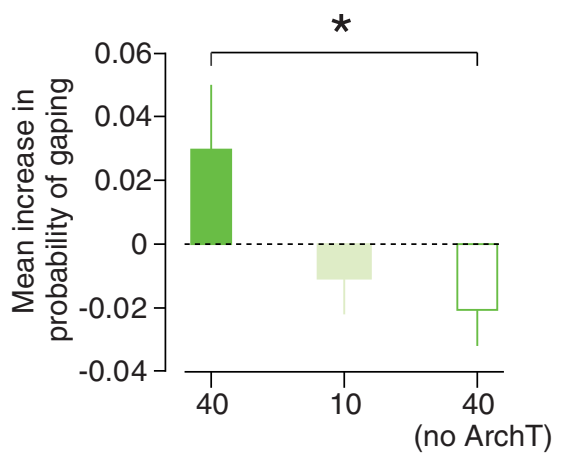

Figure 6. Impact of GC inactivation on the lick - gape transition. A bar plot illustrating the effect of GC inactivation on the probability that the animal will produce gapes in the $2.5 \mathrm{~s}$ following $\mathrm{SQ}$ delivery ( $y$-axis) for three separate experimental groups: ArchT animals exposed to $40 \mathrm{~mW}$ laser light (bright green bar), ArchT-expressing animals exposed to $10 \mathrm{~mW}$ laser light (light green bar), and virus-free animals exposed to $40 \mathrm{~mW}$ laser light (white bar with green border). The height of each bar quantifies the difference in behavior between the light-on and light-off trials for the experimental group. Positive values indicate that the light-on trials were more likely to contain gapes. Error bars in the plot represent SEs; ${ }^{*} p=0.04$.

6), an effect that was related to the degree of inactivation (i.e., laser intensity). Rats expressing ArchT were more likely to gape during the light-on trials than during the light-off trials when the laser power was set to $40 \mathrm{~mW}$ (Fig. 6, bright green bar); this dropped for a power setting of $10 \mathrm{~mW}$ (Fig. 6, pale green bar). The presence of the $40 \mathrm{~mW}$ light alone led to a further drop in the probability of gaping (Fig. 6, white bar with green edges); the difference between the control and ArchT-expressing animals was significant $\left(p=0.04, z_{(21)}=-2.09\right.$, Wilcoxon rank sum test) although small (see Discussion).

GC inactivation did not alter specific characteristics of the gape rhythm, such as the average latency of the first gape ( $p=$ $\left.0.97 ; z_{(21)}=0.03\right)$, or the variability in that latency across trials $\left(p=1.0 ; z_{(21)}=0.0\right)$. Furthermore, the loss of GC also had no discernable impact on the kinematics of individual gapes. We used video analysis to identify licks and gapes produced by four animals following deliveries of sQ. Figure $7 \mathrm{~A}$ plots the duration and frequency (1/time between successive movements) for each movement, with movements from the "light-on" trials occupying the top panel, and movements from the "light-off" trials, the bottom panel in Figure 7A. The clouds of blue dots denoting gapes in the top and bottom panels Figure $7 A$ have approximately the same location and shape; we found no significant difference in either gape duration $[97.0 \pm 31.6 \mathrm{~ms}$ with light on, $96.0 \pm 27.5$ ms with light off; $p=0.18$; Kolmogorov-Smirnov (K-S) statistic, 0.08 , K-S test] or gape frequency $(5.42 \pm 1.48 \mathrm{~Hz}$ with light on, $5.30 \pm 1.44 \mathrm{~Hz}$ with light off; $p=0.35$; K-S statistic, 0.07 , Kolmogorov-Smirnov test) between the light-on and light-off trials. Moreover, the gape detection algorithm, which was fit on data from a completely separate group of animals (see Materials and Methods), performed similarly well for the light-on and light-off trials (Fig. 7B; mean difference in $d^{\prime},-0.048$; SE, 0.29). Our results suggest that $\mathrm{GC}$ is involved in the selection of a motor rhythm (as one of several interconnected regions so involved; see Discussion), but not in the production of individual movements within that rhythm.

\section{Discussion}

In the active rat, primary GC firing broadly reflects oral behaviors such as nonspecific licks, firing that is typically interpreted as somatosensory feedback (Katz et al., 2001). Here, we show that GC plays a role in the transition from licking to gaping, as follows:
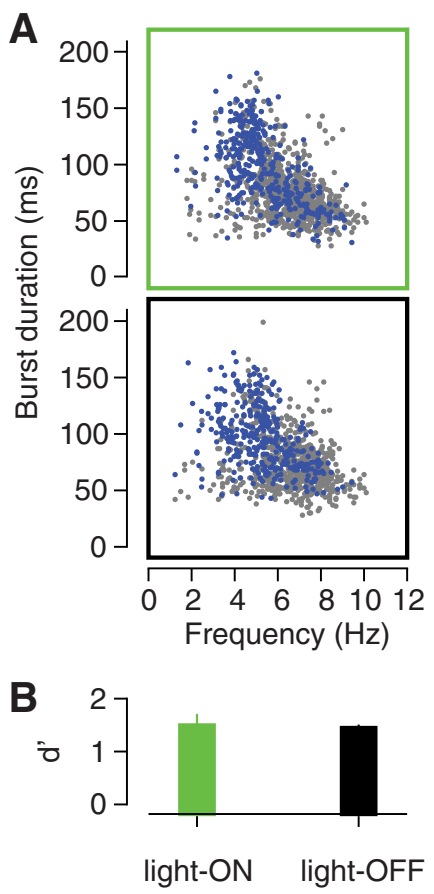

Figure 7. Impact of GC inactivation on the duration and frequency of individual licks and gapes. $\boldsymbol{A}$, Comparison of mouth movement duration and frequency in four virus-infected animals during light-on (top) and light-off (bottom) trials. Each symbol represents a separate mouth movement, with video-coded gapes in blue, and non-gapes in gray. $\boldsymbol{B}$, Performance of the gape detection algorithm for the light-on $\mathrm{s} Q$ trials (green bar) vs for the light-off $s Q$ trials (black bar). Error bars indicate the SEM across animals $(N=4)$. The laser was set to $40 \mathrm{~mW}$ for all light-on trials.

(1) palatability-related firing in GC emerges in advance of gaping; (2) GC firing is modulated before the first gape in a bout, but not before later gapes; (3) decreasing the latency of gaping decreases the latency of GC responses commensurately; and (4) inhibiting GC activity while the animal is experiencing a bitter taste causes significant changes in the likelihood of gaping.

Although the fourth finding, that $\mathrm{GCx}$ increased gaping, seems counterintuitive, it is consistent with the function of an "across-neuron pattern" decoder interpreting the output of late $\mathrm{GC}$ responses. Quinine increases the firing rates of some neurons and decreases the firing rates of others; $\mathrm{GCx}$ interfered with the increases while enhancing the decreases. This latter effect may have "dominated" the overall change, such that the overall GC output was decoded as more "quinine like." Thus might GCx increase the likelihood of gaping, just as the activation of GC neurons may increase the likelihood of behaviors consistent with high palatability (Peng et al., 2015).

On the other hand, while GCx altered the probability that the animal would gape at all in response to an aversive taste, it had no impact on the frequency and duration of individual gapes (see also point 2 above). In this, our findings are consistent with studies demonstrating that the mechanics of individual movements are determined by the brainstem CPG (Travers et al., 2000; Chen et al., 2001). It remains possible that other forebrain areas (e.g., orofacial motor cortex) do contribute to the driving of specific muscles; however, mouth movements can be elicited by electrical stimulation of either GC or the orofacial motor cortex; motor cortical stimulation causes specific movements, while GC stimulation, consistent with our findings, "kicks off" mouth movements without driving individual movements themselves (Sasamoto et al., 1990). 
Both areas project directly to the taste CPG (Zhang and Sasamoto, 1990) and may comprise complementary pathways in the control of orofacial behaviors.

Our results are consistent with results from the lobster stomatogastric ganglion (Marder and Bucher, 2007), leech swim (Crisp and Mesce, 2004), Aplysia feeding system (Dacks and Weiss, 2013), and rat vibrissal systems (Hattox et al., 2003). In each of these systems, basic rhythms produced autonomously by a CPG are, in situ, deeply influenced by neuromodulation. Analogously, we propose that feedback from GC could select/modulate the motor pattern produced by the taste brainstem CPG (Chandler et al., 1985). As cholinergic, serotonergic, and adrenergic projections permeate the rodent medullary reticular formation (Holmes et al., 1994; Nasse and Travers, 2014), forebrain areas could modulate orofacial behaviors by altering neuromodulator signaling in taste CPG, altering the dynamics of the circuit and thereby influencing orofacial movements. Consistent with this speculation are data demonstrating that serotonin depletion impairs conditioned gaping (Limebeer and Parker, 2000; Limebeer et al., 2004).

We did not examine movements associated with the consumption of palatable fluids (e.g., LTMs; Grill and Norgren, 1978a; Berridge, 2000), because gapes are more reliably isolated from activity in the digastric muscle, which is a mouth (and not a tongue) mover. LTMs and gapes are characterized by distinct patterns of muscle activation (Travers and Norgren, 1986; Dinardo and Travers, 1994), and could conceivably operate by distinct neural mechanisms. We consider this possibility unlikely, however, because electrophysiological, pharmacological, and modeling data suggest that there is considerable, and possibly even complete, overlap in the CPG circuits for LTMs and gapes (Travers et al., 2000; Chen et al., 2001; Chen and Travers, 2003; Venugopal et al., 2007). GC single-neuron responses code palatability across the entire spectrum of pleasant and aversive tastes as well (Yamamoto et al., 1985; Ogawa et al., 1992; Hanamori et al., 1998; Katz et al., 2001; Sadacca et al., 2012), rather than simply coding aversion. Finally, our EMG data enable us to recognize at least the palatability-correlated spectral signature of LTMs (Fig. $2 A, B)$, which emerge with the same latency as gape-related rhythms. While direct test awaits further study, it is reasonable to suspect equivalent GC involvement in egestive and ingestive oral behaviors. Similarly, while neural responses are quite different when animals acquire their own tastes (Stapleton et al., 2006; Crouzet et al., 2015), there is nothing in the current literature that suggests that GC would not be involved in behavior selection in different species and contexts.

GC clearly does not act alone in this regard, however; it is almost certainly one part of a broadly distributed network modulating the taste CPG. Amygdalar, hypothalamic, visceral cortical, and BNST neurons all project directly or indirectly to the taste CPG (Zhang and Sasamoto, 1990; Shammah-Lagnado et al., 1992; Travers et al., 1997); the first two produce palatabilityrelated taste responses (Yamamoto et al., 1989; Nishijo et al., 1998; Fontanini et al., 2009; Sadacca et al., 2012; Li et al., 2013), and stimulation of the first three impacts taste behavior (Berridge and Valenstein, 1991; Ganaraja and Jeganathan, 2000; Peng et al., 2015). Brainstem taste regions as well, which loop directly back to the oromotor CPG (Shammah-Lagnado et al., 1992; Halsell et al., 1996) and can sustain gaping even in the face of decerebration (Grill and Norgren, 1978b), undoubtedly play a major role in the driving of gapes.

The involvement of multiple brain areas may explain why optogenetic inactivation has only a modest effect on gaping. If multiple regions work together to process quinine, it is likely that motor function degrades gracefully with network manipulation (small perturbations $\rightarrow$ small effects); it is probably only our use of optogenetics, which precluded the need for a 1-2 week recovery period between lesion and test and allowed us to perform within-session comparisons, that allowed us to observe a previously hidden role of GC in this process (Grill and Norgren, 1978b; Hashimoto and Spector, 2014).

GC has previously been suggested to convey contextual information to the CPG (Gallo et al., 1992; Schafe and Bernstein, 1998; Saddoris et al., 2009; Veldhuizen et al., 2011; Samuelsen et al., 2012; Gardner and Fontanini, 2014). The fact that rats do not respond identically to multiple presentations of the same taste solution (in some $1 \mathrm{~mm}$ quinine trials, gapes appeared within $0.5 \mathrm{~s}$ following taste delivery; in others, no gapes were detected for at least $2.5 \mathrm{~s}$ ) might at least partially reflect fluctuations in the cognitive state of the animal over the course of the experimental session. Perhaps, during GCx, the taste circuit is less able to incorporate top-down information, such that the "reduced" system regresses toward the "default mode" of gaping identically to every application of the aversive taste. These speculations are consistent with a previous study (Fontanini and Katz, 2006) showing that as rats become less attentive, GC responses to quinine and sucrose become more polarized.

Of course, the impact of GCx was likely also limited by methodology. Although GFP diffused across a broad swath of GC, the laser intensity we used only inactivated neurons within a $1 \mathrm{~mm}$ sphere around the tip of the optic fiber (Han et al., 2011), <33\% of the extent of GC in the caudal-rostral axis alone (Kosar et al., 1986); furthermore, gene delivery using viral vectors is subject to considerable between-animal variability in the levels of infection and gene expression (Packer et al., 2013), such that even the high levels of fluorescence (see Materials and Methods) and behavioral efficacy (see CTA results) achieved here do not ensure the efficacy of illumination.

Finally, the high laser intensity necessary for in vivo wholeregion inactivation itself slightly reduced the likelihood of gaping (Fig. 6), causing our optogenetic result to appear smaller than it really is. Perhaps the $40 \mathrm{~mW}$ laser caused a mild intrinsic change in neural excitability that runs counter to the impact of inhibition via ArchT-a possibility consistent with results from another recent study (Maier et al., 2015). Alternatively, perhaps the bleed of laser light into the chamber during light-on trials slightly reduced the attention paid to the taste. Regardless, GCx counteracted this trend, significantly increasing the probability of gaping.

These considerations imply that optogenetic GCx was only partial, a conclusion consistent with the fact that this inactivation was less effective in blocking conditioned taste aversion than either electrolytic lesions (Schafe and Bernstein, 1998) or pharmacological inactivation (Stone et al., 2005), both of which have a greater spatial spread (Arikan et al., 2002; Fortis-Santiago et al., 2010). More comprehensive inactivation would likely lead to greater changes in motor responses (but see Hashimoto and Spector, 2014).

Finally, this work joins a growing literature (Niell and Stryker, 2010; Oswald and Urban, 2012; Petersen and Crochet, 2013) hinting at complexities in the relationship between sensory and motor systems. Here, we uncover and characterize a direct link between activity in sensory cortex and movement. Our results favor an integrated model in which sensory and motor components work in conjunction to drive behavior, rather than as a sequential relay model. 


\section{References}

Arikan R, Blake NM, Erinjeri JP, Woolsey TA, Giraud L, Highstein SM (2002) A method to measure the effective spread of focally injected muscimol into the central nervous system with electrophysiology and light microscopy. J Neurosci Methods 118:51-57. CrossRef Medline

Babadi B, Brown EN (2014) A review of multitaper spectral analysis. IEEE Trans Biomed Eng 61:1555-1564. CrossRef Medline

Berridge KC (2000) Measuring hedonic impact in animals and infants: microstructure of affective taste reactivity patterns. Neurosci Biobehav Rev 24:173-198. CrossRef Medline

Berridge KC, Valenstein ES (1991) What psychological process mediates feeding evoked by electrical stimulation of the lateral hypothalamus? Behav Neurosci 105:3-14. CrossRef Medline

Berridge KC, Flynn FW, Schulkin J, Grill HJ (1984) Sodium depletion enhances salt palatability in rats. Behav Neurosci 98:652-660. CrossRef Medline

Chandler SH, Goldberg LJ, Lambert RW (1985) The effects of orofacial sensory input on spontaneously occurring and apomorphine-induced rhythmical jaw movements in the anesthetized guinea pig. Neurosci Lett 53:45-49. CrossRef Medline

Chen Z, Travers JB (2003) Inactivation of amino acid receptors in medullary reticular formation modulates and suppresses ingestion and rejection responses in the awake rat. Am J Physiol Regul Integr Comp Physiol 285:R68-R83. CrossRef Medline

Chen Z, Travers SP, Travers JB (2001) Muscimol infusions in the brain stem reticular formation reversibly block ingestion in the awake rat. Am J Physiol Regul Integr Comp Physiol 280:R1085-R1094. Medline

Cramer NP, Keller A (2006) Cortical control of a whisking central pattern generator. J Neurophysiol 96:209-217. CrossRef Medline

Crisp KM, Mesce KA (2004) A cephalic projection neuron involved in locomotion is dye coupled to the dopaminergic neural network in the medicinal leech. J Exp Biol 207:4535-4542. CrossRef Medline

Crouzet SM, Busch NA, Ohla K (2015) Taste quality decoding parallels taste sensations. Curr Biol 25:890-896. CrossRef Medline

Dacks AM, Weiss KR (2013) Latent modulation: a basis for non-disruptive promotion of two incompatible behaviors by a single network state. J Neurosci 33:3786-3798. CrossRef Medline

Dinardo LA, Travers JB (1994) Hypoglossal neural activity during ingestion and rejection in the awake rat. J Neurophysiol 72:1181-1191. Medline

Dunn LT, Everitt BJ (1988) Double dissociations of the effects of amygdala and insular cortex lesions on conditioned taste aversion, passive avoidance, and neophobia in the rat using the excitotoxin ibotenic acid. Behav Neurosci 102:3-23. CrossRef Medline

Duysens J, Van de Crommert HW (1998) Neural control of locomotion; The central pattern generator from cats to humans. Gait Posture 7:131-141. CrossRef Medline

Fontanini A, Katz DB (2006) State-dependent modulation of time-varying gustatory responses. J Neurophysiol 96:3183-3193. CrossRef Medline

Fontanini A, Grossman SE, Figueroa JA, Katz DB (2009) Distinct subtypes of basolateral amygdala taste neurons reflect palatability and reward. J Neurosci 29:2486-2495. CrossRef Medline

Fortis-Santiago Y, Rodwin BA, Neseliler S, Piette CE, Katz DB (2010) State dependence of olfactory perception as a function of taste cortical inactivation. Nat Neurosci 13:158-159. CrossRef Medline

Friesen WO, Kristan WB (2007) Leech locomotion: swimming, crawling, and decisions. Curr Opin Neurobiol 17:704-711. CrossRef Medline

Gallo M, Roldan G, Bures J (1992) Differential involvement of gustatory insular cortex and amygdala in the acquisition and retrieval of conditioned taste aversion in rats. Behav Brain Res 52:91-97. CrossRef Medline

Ganaraja B, Jeganathan PS (2000) Effect of basolateral amygdala and ventromedial hypothalamic lesions on ingestion and taste preference in rat. Indian J Med Res 112:65-70. Medline

Gardner MP, Fontanini A (2014) Encoding and tracking of outcomespecific expectancy in the gustatory cortex of alert rats. J Neurosci 34: 13000-13017. CrossRef Medline

Grill HJ, Norgren R (1978a) The taste reactivity test. I. Mimetic responses to gustatory stimuli in neurologically normal rats. Brain Res 143:263-279. CrossRef Medline

Grill HJ, Norgren R (1978b) The taste reactivity test. II. Mimetic responses to gustatory stimuli in chronic thalamic and chronic decerebrate rats. Brain Res 143:281-297. CrossRef Medline
Grillner S (1985) Neurobiological bases of rhythmic motor acts in vertebrates. Science 228:143-149. CrossRef Medline

Halsell CB, Travers SP, Travers JB (1996) Ascending and descending projections from the rostral nucleus of the solitary tract originate from separate neuronal populations. Neuroscience 72:185-197. CrossRef Medline

Hanamori T, Kunitake T, Kato K, Kannan H (1998) Responses of neurons in the insular cortex to gustatory, visceral, and nociceptive stimuli in rats. J Neurophysiol 79:2535-2545. Medline

Han X, Chow BY, Zhou H, Klapoetke NC, Chuong A, Rajimehr R, Yang A, Baratta MV, Winkle J, Desimone R, Boyden ES (2011) A high-light sensitivity optical neural silencer: development and application to optogenetic control of non-human primate cortex. Front Syst Neurosci 5:18. CrossRef Medline

Hashimoto K, Spector AC (2014) Extensive lesions in the gustatory cortex in the rat do not disrupt the retention of a presurgically conditioned taste aversion and do not impair unconditioned concentration-dependent licking of sucrose and quinine. Chem Senses 39:57-71. CrossRef Medline

Hattox AM, Priest CA, Keller A (2002) Functional circuitry involved in the regulation of whisker movements. J Comp Neurol 442:266-276. CrossRef Medline

Hattox A, Li Y, Keller A (2003) Serotonin regulates rhythmic whisking. Neuron 39:343-352. CrossRef Medline

Holmes CJ, Mainville LS, Jones BE (1994) Distribution of cholinergic, GABAergic and serotonergic neurons in the medial medullary reticular formation and their projections studied by cytotoxic lesions in the cat. Neuroscience 62:1155-1178. CrossRef Medline

Holstege G, Kuypers HG, Dekker JJ (1977) The organization of the bulbar fibre connections to the trigeminal, facial and hypoglossal motor nuclei. II. An autoradiographic tracing study in cat. Brain 100:264-286. Medline

Jones LM, Fontanini A, Sadacca BF, Miller P, Katz DB (2007) Natural stimuli evoke dynamic sequences of states in sensory cortical ensembles. Proc Natl Acad Sci U S A 104:18772-18777. CrossRef Medline

Jordan LM, Slawińska U (2011) Chapter 12-modulation of rhythmic movement: control of coordination. Prog Brain Res 188:181-195. CrossRef Medline

Katz DB, Simon SA, Nicolelis MA (2001) Dynamic and multimodal responses of gustatory cortical neurons in awake rats. J Neurosci 21: 4478-4489. Medline

Kiefer SW, Orr MR (1992) Taste avoidance, but not aversion, learning in rats lacking gustatory cortex. Behav Neurosci 106:140-146. CrossRef Medline

Kosar E, Grill HJ, Norgren R (1986) Gustatory cortex in the rat. I. Physiological properties and cytoarchitecture. Brain Res 379:329-341. CrossRef Medline

Li JX, Yoshida T, Monk KJ, Katz DB (2013) Lateral hypothalamus contains two types of palatability-related taste responses with distinct dynamics. J Neurosci 33:9462-9473. CrossRef Medline

Limebeer CL, Parker LA (2000) The antiemetic drug ondansetron interferes with lithium-induced conditioned rejection reactions, but not lithiuminduced taste avoidance in rats. J Exp Psychol Anim Behav Process 26: 371-384. CrossRef Medline

Limebeer CL, Parker LA, Fletcher PJ (2004) 5,7-dihydroxytryptamine lesions of the dorsal and median raphe nuclei interfere with lithiuminduced conditioned gaping, but not conditioned taste avoidance, in rats. Behav Neurosci 118:1391-1399. CrossRef Medline

Loeb GE, Gans C (1986) Electromyography for experimentalists. Chicago: University of Chicago.

Maier JX, Katz DB (2013) Neural dynamics in response to binary taste mixtures. J Neurophysiol 109:2108-2117. CrossRef Medline

Maier JX, Blankenship ML, Barry NC, Richards SE, Katz DB (2014) Stability and flexibility of the message carried by semiochemical stimuli, as revealed by devaluation of carbon disulfide followed by social transmission of food preference. Behav Neurosci 128:413-418. CrossRef Medline

Maier JX, Blankenship ML, Li JX, Katz DB (2015) Multisensory connectivity affects olfactory processing. Curr Biol 25:2642-2650. CrossRef

Marder E, Bucher D (2007) Understanding circuit dynamics using the stomatogastric nervous system of lobsters and crabs. Annu Rev Physiol 69: 291-316. CrossRef Medline

Marder E, Bucher D, Schulz DJ, Taylor AL (2005) Invertebrate central pattern generation moves along. Curr Biol 15:R685-R699. CrossRef Medline Misanin JR, Hinderliter CF (1994) Efficacy of lithium chloride in the taste- 
aversion conditioning of young-adult and old-age rats. Psychol Rep 75: 267-271. CrossRef Medline

Moraga-Amaro R, Cortés-Rojas A, Simon F, Stehberg J (2014) Role of the insular cortex in taste familiarity. Neurobiol Learn Mem 109:37-45. CrossRef Medline

Moran A, Katz DB (2014) Sensory cortical population dynamics uniquely track behavior across learning and extinction. J Neurosci 34:1248-1257. CrossRef Medline

Nachman M, Ashe JH (1973) Learned taste aversions in rats as a function of dosage, concentration, and route of administration of LiCl. Physiol Behav 10:73-78. CrossRef Medline

Nasse JS, Travers JB (2014) Adrenoreceptor modulation of oromotor pathways in the rat medulla. J Neurophysiol 112:580-593. CrossRef Medline

Niell CM, Stryker MP (2010) Modulation of visual responses by behavioral state in mouse visual cortex. Neuron 65:472-479. CrossRef Medline

Nishijo H, Uwano T, Tamura R, Ono T (1998) Gustatory and multimodal neuronal responses in the amygdala during licking and discrimination of sensory stimuli in awake rats. J Neurophysiol 79:21-36. Medline

Ogawa H, Hasegawa K, Murayama N (1992) Difference in taste quality coding between two cortical taste areas, granular and dysgranular insular areas, in rats. Exp Brain Res 91:415-424. Medline

Oswald AM, Urban NN (2012) Interactions between behaviorally relevant rhythms and synaptic plasticity alter coding in the piriform cortex. J Neurosci 32:6092-6104. CrossRef Medline

Packer AM, Roska B, Häusser M (2013) Targeting neurons and photons for optogenetics. Nat Neurosci 16:805-815. CrossRef Medline

Paxinos G, Watson C (2007) The rat brain in stereotaxic coordinates, Ed 6. Amsterdam, Boston; Academic/Elsevier.

Peng Y, Gillis-Smith S, Jin H, Tränkner D, Ryba NJ, Zuker CS (2015) Sweet and bitter taste in the brain of awake behaving animals. Nature 527: 512-515. CrossRef Medline

Petersen CC, Crochet S (2013) Synaptic computation and sensory processing in neocortical layer 2/3. Neuron 78:28-48. CrossRef Medline

Piette CE, Baez-Santiago MA, Reid EE, Katz DB, Moran A (2012) Inactivation of basolateral amygdala specifically eliminates palatability-related information in cortical sensory responses. J Neurosci 32:9981-9991. CrossRef Medline

Roman C, Nebieridze N, Sastre A, Reilly S (2006) Effects of lesions of the bed nucleus of the stria terminalis, lateral hypothalamus, or insular cortex on conditioned taste aversion and conditioned odor aversion. Behav Neurosci 120:1257-1267. CrossRef Medline

Sadacca BF, Rothwax JT, Katz DB (2012) Sodium concentration coding gives way to evaluative coding in cortex and amygdala. J Neurosci 32: 9999-10011. CrossRef Medline

Saddoris MP, Holland PC, Gallagher M (2009) Associatively learned representations of taste outcomes activate taste-encoding neural ensembles in gustatory cortex. J Neurosci 29:15386-15396. CrossRef Medline

Samuelsen CL, Gardner MP, Fontanini A (2012) Effects of cue-triggered expectation on cortical processing of taste. Neuron 74:410-422. CrossRef Medline

Sasamoto K, Zhang G, Iwasaki M (1990) Two types of rhythmical jaw movements evoked by stimulation of the rat cortex. Shika Kiso Igakkai Zasshi 32:57-68. Medline

Schafe GE, Bernstein IL (1998) Forebrain contribution to the induction of a brainstem correlate of conditioned taste aversion. II. Insular (gustatory) cortex. Brain Res 800:40-47. CrossRef Medline

Shammah-Lagnado SJ, Costa MS, Ricardo JA (1992) Afferent connections of the parvocellular reticular formation: a horseradish peroxidase study in the rat. Neuroscience 50:403-425. CrossRef Medline

Spector AC, Breslin P, Grill HJ (1988) Taste reactivity as a dependent measure of the rapid formation of conditioned taste aversion: a tool for the neural analysis of taste-visceral associations. Behav Neurosci 102: 942-952. CrossRef Medline

Stapleton JR, Lavine ML, Wolpert RL, Nicolelis MA, Simon SA (2006) Rapid taste responses in the gustatory cortex during licking. J Neurosci 26: 4126-4138. CrossRef Medline

Stehberg J, Moraga-Amaro R, Simon F (2011) The role of the insular cortex in taste function. Neurobiol Learn Mem 96:130-135. CrossRef Medline

Stone ME, Grimes BS, Katz DB (2005) Hippocampal inactivation enhances taste learning. Learn Mem 12:579-586. CrossRef Medline

Travers JB, Norgren R (1986) Electromyographic analysis of the ingestion and rejection of sapid stimuli in the rat. Behav Neurosci 100:544-555. CrossRef Medline

Travers JB, Dinardo LA, Karimnamazi H (1997) Motor and premotor mechanisms of licking. Neurosci Biobehav Rev 21:631-647. CrossRef Medline

Travers JB, DiNardo LA, Karimnamazi H (2000) Medullary reticular formation activity during ingestion and rejection in the awake rat. Exp Brain Res 130:78-92. CrossRef Medline

Travers JB, Yoo JE, Chandran R, Herman K, Travers SP (2005) Neurotransmitter phenotypes of intermediate zone reticular formation projections to the motor trigeminal and hypoglossal nuclei in the rat. J Comp Neurol 488:28-47. CrossRef Medline

Veldhuizen MG, Douglas D, Aschenbrenner K, Gitelman DR, Small DM (2011) The anterior insular cortex represents breaches of taste identity expectation. J Neurosci 31:14735-14744. CrossRef Medline

Venugopal S, Travers JB, Terman DH (2007) A computational model for motor pattern switching between taste-induced ingestion and rejection oromotor behaviors. J Comput Neurosci 22:223-238. CrossRef Medline

Vidal-Gadea AG, Jing XJ, Simpson D, Dewhirst OP, Kondoh Y, Allen R, Newland PL (2010) Coding characteristics of spiking local interneurons during imposed limb movements in the locust. J Neurophysiol 103: 603-615. CrossRef Medline

Yamamoto T, Yuyama N, Kato T, Kawamura Y (1985) Gustatory responses of cortical neurons in rats. II. Information processing of taste quality. J Neurophysiol 53:1356-1369. Medline

Yamamoto T, Matsuo R, Kiyomitsu Y, Kitamura R (1989) Response properties of lateral hypothalamic neurons during ingestive behavior with special reference to licking of various taste solutions. Brain Res 481: 286-297. CrossRef Medline

Zhang F, Gradinaru V, Adamantidis AR, Durand R, Airan RD, de Lecea L, Deisseroth K (2010) Optogenetic interrogation of neural circuits: technology for probing mammalian brain structures. Nat Protoc 5:439-456. CrossRef Medline

Zhang GX, Sasamoto K (1990) Projections of two separate cortical areas for rhythmical jaw movements in the rat. Brain Res Bull 24:221-230. CrossRef Medline 